\title{
Photoinduced photoluminescence-variations of CdSe quantum dots in polymer solutions
}
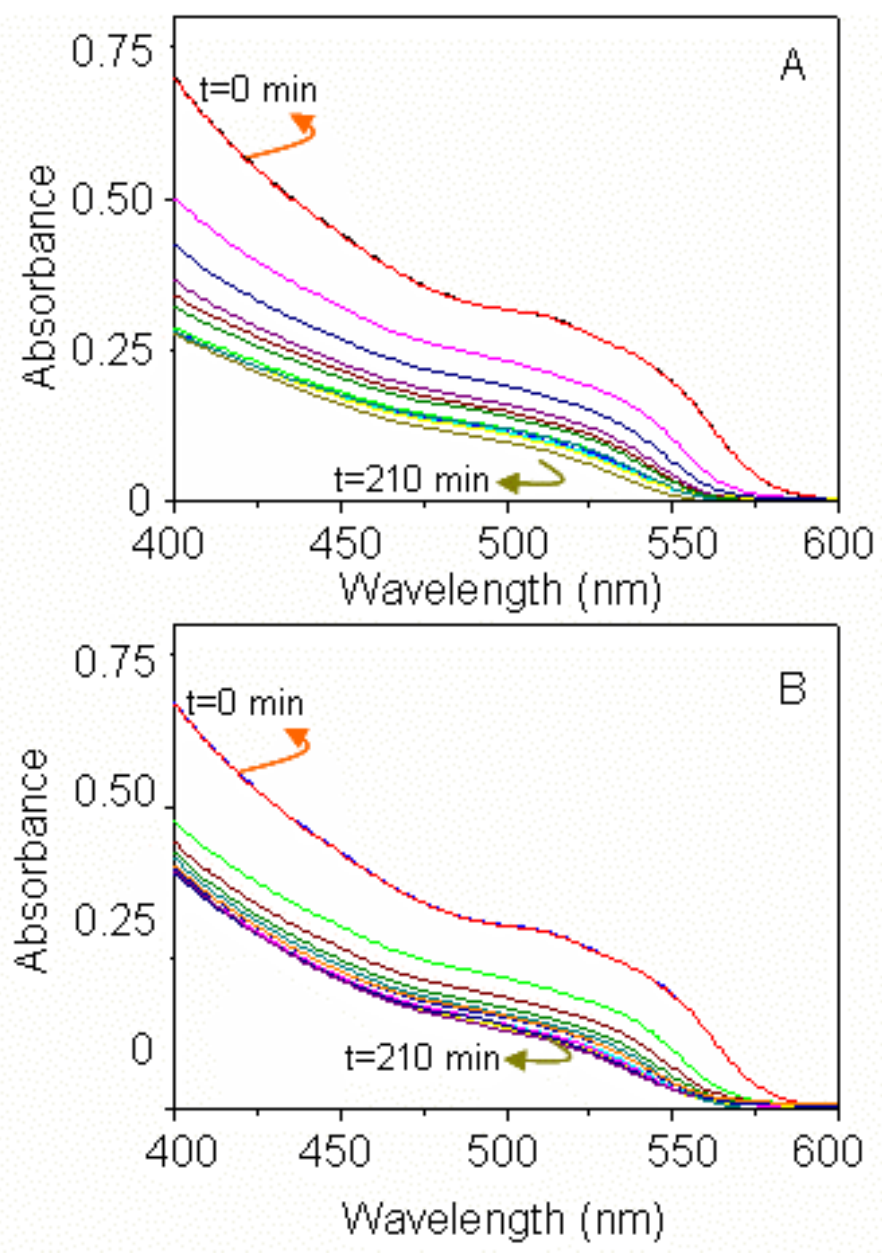

Figure S1. Absorption spectra of CdSe QD solutions in $\mathrm{CHCl}_{3}$ under photoactivation at $400 \mathrm{~nm}$ : (A) in the absence polymer, and (B) in the presence of PDMS. The absence of characteristic band edge absorption features was probably due to a size distribution of QDs. 


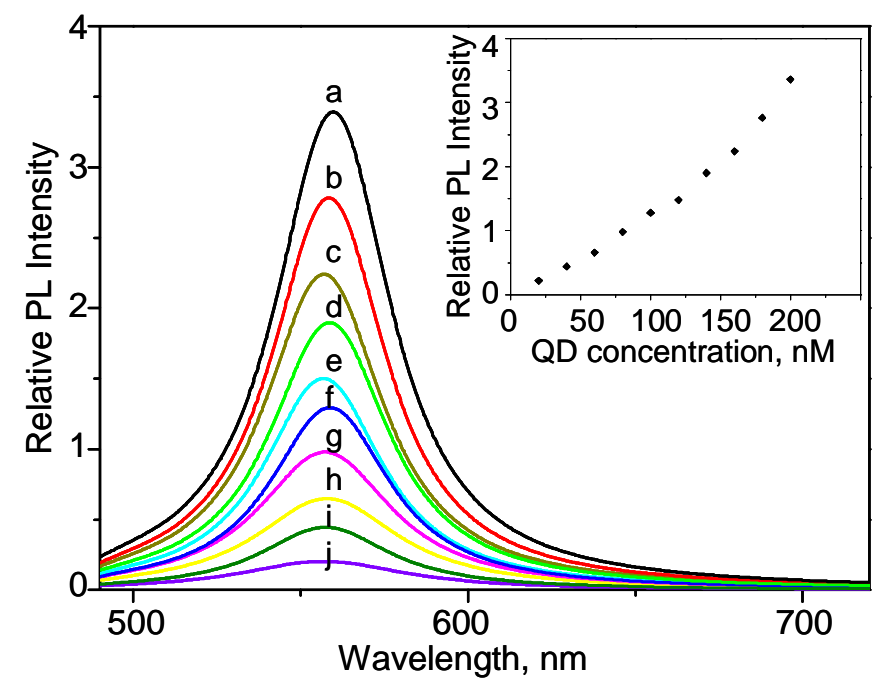

Figure S2. PL spectra of CdSe QD solutions in $\mathrm{CHCl}_{3}$ as a function of dilution: (a) 200, (b) 180, (c) 160, (d) 140, (e) 120, (f) 100, (g) 80, (h) 60, (i) 40, and (j) $20 \mathrm{nM}$. Inset: PL intensity values at emission maxima vs QD concentration. 